\title{
Cellular Fatty Acid Compositions of Moraxella anatipestifer and Legionella pneumophila
}

\author{
MARY ANN LAMBERT* AND C. WAYNE MOSS \\ Division of Bacterial Diseases, Center for Infectious Diseases, Centers for Disease Control, Atlanta, Georgia 30333
}

\begin{abstract}
In contrast to results from a recent study, we found the fatty acid composition of Legionella pneumophila to be distinct from the fatty acid composition of Moraxella anatipestifer. $M$. anatipestifer contained large amounts (50\%) of 13-methyltetradecanoic acid and smaller amounts ( 5 to $22 \%$ ) of branched-chain hydroxy acids, whereas L. pneumophila contained 14-methylpentadecanoic acid as the major component (30\%), with no or trace amounts $(<1 \%)$ of 13 -methyltetradecanoic and hydroxy acids. Similar fatty acid results were obtained on two different growth media.
\end{abstract}

In a recent study of the cellular fatty acids of Moraxella species, Sugimoto et al. (9) reported that the overall fatty acid composition of Moraxella anatipestifer was similar to that of Legionella pneumophila. Both of these organisms were reported to contain large amounts of branched-chain fatty acids, with 13-methyltetradecanoic acid (i-15:0 acid) being the major component at concentrations ranging from 38 to $55 \%$. In contrast, during the last 7 years workers in our laboratory have examined more than 500 isolates of Legionella, and we have never observed more than small $(2 \%)$ to trace amounts of $\mathrm{i}-15: 0$ acid in any of these isolates $(3,4,6$, 7). A possible factor to account for this major difference is that Sugimoto et al. (9) grew L. pneumophila on Eugon agar which was supplemented with $5 \%$ Fildes pepsin-digested sheep blood, whereas we tested our isolates after growth on charcoal-yeast extract agar (1) or buffered charcoal-yeast extract (BCYE) agar (8). In this study, we compared the fatty acid compositions of $L$. pneumophila and $M$. anatipestifer after growth on Eugon agar (BBL Microbiology Systems, Cockeysville, Md.) supplemented with 5\% Fildes enrichment (EA-FE medium; Difco Laboratories, Detroit, Mich.) and on BCYE agar.

$M$. anatipestifer strains ATCC $11845^{\mathrm{T}}(\mathrm{T}=$ type strain) and KC534 and L. pneumophila strains ATCC $33152^{\mathrm{T}}$ and ATCC 33154 were inoculated on each of the two media and incubated in air, in 5\% oxygen, and in a candle extinction jar at $35^{\circ} \mathrm{C}$ for 72 to $96 \mathrm{~h}$. The cells were harvested, and the fatty acid methyl esters were prepared by methods which have been described previously (5). Analysis, identification, and quantitation of the fatty acid methyl esters were done as described previously $(2,5)$ by using a $50-\mathrm{m}$ by $0.2-\mathrm{mm}$ (inside diameter) fused silica capillary column with cross-linked methyl silicone (type OV-101; Hewlett Packard Co., Avondale, $\mathrm{Pa}$.) as the stationary phase.

Each of the four strains grew well on BCYE agar under each of the conditions of incubation. The two strains of $L$. pneumophila grew poorly or not at all on EA-FE medium when plates were incubated in air or 5\% oxygen; however, light growth was obtained when plates were incubated in a candle jar. The cellular fatty acid data for the four strains incubated on the two media for $72 \mathrm{~h}$ in a candle jar are shown in Table 1.

On each medium, the major fatty acid in both strains of $M$. anatipestifer was i-15:0 acid, and this compound comprised

\footnotetext{
* Corresponding author.
}

at least one-third of the total acids. The next most abundant acids in this organism were 3-hydroxy-15-methylhexadecanoic (3-OH-i-17:0), 3-hydroxy-13-methyltetradecanoic (3-OH-i-15:0), 12-methyltetradecanoic (a-15:0), and 11-methyldodecanoic (i-13:0) acids. Cells grown on EA-FE medium also contained small amounts $(2 \%)$ of hexadecanoic (16:0), 14-methylhexadecanoic (a-17:1), and oleic $\left(18: 1, \Delta^{9}\right)$ acids, whereas cells grown on BCYE agar contained 5 to $8 \%$ 3-hydroxy-14-methylpentadecanoic acid (3-OH-i-16:0) and 1

TABLE 1. Cellular fatty acid compositions of $M$. anatipestifer and $L$. pneumophila

\begin{tabular}{|c|c|c|c|c|c|c|c|c|}
\hline \multirow{2}{*}{ Fatty acid ${ }^{a}$} & \multicolumn{2}{|c|}{$\begin{array}{c}\text { M. anatipes- } \\
\text { tifer ATCC } \\
11845^{\mathrm{T}}\end{array}$} & \multicolumn{2}{|c|}{$\begin{array}{l}\text { M. anatipes- } \\
\text { tifer KC534 }\end{array}$} & \multicolumn{2}{|c|}{$\begin{array}{l}\text { L. pneumo- } \\
\text { phila ATCC } \\
33152^{\mathrm{T}}\end{array}$} & \multicolumn{2}{|c|}{$\begin{array}{l}\text { L. pneumo- } \\
\text { phila ATCC } \\
\quad 33154\end{array}$} \\
\hline & $\begin{array}{l}\text { EA-FE } \\
\text { medium }\end{array}$ & $\begin{array}{c}\text { BCYE } \\
\text { agar }\end{array}$ & $\begin{array}{l}\text { EA-FE } \\
\text { medium }\end{array}$ & $\begin{array}{c}\text { BCYE } \\
\text { agar }\end{array}$ & $\begin{array}{l}\text { EA-FE } \\
\text { medium }\end{array}$ & $\begin{array}{l}\mathrm{BCY} \\
\text { agar }\end{array}$ & $\begin{array}{l}\text { EA-FE } \\
\text { medium }\end{array}$ & $\begin{array}{l}\text { BCYE } \\
\text { agar }\end{array}$ \\
\hline $\mathrm{i}-13: 0$ & $6^{b}$ & 4 & 7 & 3 & - & - & - & - \\
\hline$a-13: 0$ & $\mathrm{~T}$ & 1 & $\mathrm{~T}$ & 1 & - & - & - & - \\
\hline Un & - & 2 & - & - & - & - & - & - \\
\hline $\mathrm{i}-14: 0$ & $\mathrm{~T}$ & 6 & $\mathrm{~T}$ & 4 & 5 & 6 & 5 & 6 \\
\hline $\mathrm{i}-15: 0$ & 53 & 34 & 59 & 48 & - & $\mathrm{T}$ & - & $\mathrm{T}$ \\
\hline$a-15: 0$ & 5 & 15 & 6 & 10 & 16 & 20 & 12 & 12 \\
\hline $15: 1$ & - & - & - & - & - & 2 & - & 2 \\
\hline $15: 0$ & - & 3 & - & 2 & - & 1 & - & $\mathrm{T}$ \\
\hline $\mathrm{i}-16: 1$ & - & - & - & - & 3 & 5 & 1 & 3 \\
\hline $\mathrm{i}-16: 0$ & - & 3 & - & 2 & 31 & 35 & 28 & 35 \\
\hline $16: 1$ & - & - & - & - & 11 & 13 & 12 & 15 \\
\hline $16: 0$ & 2 & $\mathrm{~T}$ & 2 & 1 & 15 & 3 & 17 & 5 \\
\hline $3-\mathrm{OH}-\mathrm{i}-15: 0$ & 8 & 6 & 6 & 5 & - & - & - & - \\
\hline a-17:1 & 2 & 2 & 2 & 2 & - & 1 & - & 1 \\
\hline a-17:0 & - & - & - & - & 8 & 10 & 5 & 8 \\
\hline $17: 0$ сус & - & - & - & - & - & - & - & 2 \\
\hline $17: 0$ & - & - & - & - & - & 1 & - & 1 \\
\hline $3-\mathrm{OH}-\mathrm{i}-16: 0$ & - & 8 & - & 5 & - & - & - & - \\
\hline $18: 2$ & $\mathrm{~T}$ & - & $\mathrm{T}$ & - & 4 & - & - & - \\
\hline $18: 1, \Delta^{9}$ & 2 & - & 2 & - & 7 & - & 6 & - \\
\hline $18: 0$ & $\mathrm{~T}$ & $\mathrm{~T}$ & - & - & - & 2 & 8 & 3 \\
\hline $3-\mathrm{OH}-\mathrm{i}-17: 0$ & 22 & 16 & 16 & 17 & - & - & - & - \\
\hline 19:0 & - & - & - & - & - & $\mathrm{T}$ & - & 2 \\
\hline $20: 0$ & - & - & - & 一 & - & 1 & 6 & 4 \\
\hline $21: 0$ & - & - & - & - & - & - & - & 1 \\
\hline
\end{tabular}

$a$ The number to the left of the colon is the number of carbon atoms; the number to the right of the colon is the number of double bonds. $\mathrm{i}$, iso branched-chain acid; a, anteiso branched-chain acid; Un, unidentified; 3-OH, hydroxyl group at carbon atom $3 ;$ cyc, cyclopropane acid; $\Delta^{9}$, double bond a the $9-10$ position.

${ }^{b}$ Values are the percentages of the total fatty acids and are arithmetic means of at least two determinations. $\mathrm{T},<1 \% ;-$, not detected. 
to 6\% 10-methyldodecanoic (a-13:0), 12-methyltridecanoic (i-14:0), pentadecanoic (15:0), 14-methylpentadecanoic (i$16: 0$ ), and a-17:1 acids. Overall, these results are very similar to those reported by Sugimoto et al. (9) for $M$. anatipestifer.

The major fatty acid in cells of $L$. pneumophila grown on both media was i-16:0 acid; the next most abundant were a-15:0, hexadecenoic (16:1), 16:0, a-17:0, i-14:0, and octadecanoic $(18: 0)$ acids. Only trace amounts $(<1 \%)$ of $\mathrm{i}-15: 0$ acid or 15-methylhexadecanoic (i-17:0) acid were found in this species, which is consistent with our previous results $(3$, $4,6,7)$. Thus, we conclude that the fatty acid composition of $L$. pneumophila is completely different from that of $M$. anatipestifer; $L$. pneumophila contains $\mathrm{i}-16: 0$ acid as the major fatty acid and contains only trace amounts of $\mathrm{i}-15: 0$ acid, which is the major acid in $M$. anatipestifer. The latter organism also contains $3-\mathrm{OH}-\mathrm{i}-15: 0,3-\mathrm{OH}-\mathrm{i}-16: 0$, and $3-\mathrm{OH}-$ i-17:0 acids, compounds which were not detected in $L$. pneumophila.

The differences with $L$. pneumophila ATCC 33154 observed in our study and in the study of Sugimoto et al. (9) were not due to medium effects, strain differences, or incubation conditions, as these were the same in both studies. It is possible that Sugimoto et al. (9) misidentified i15:0 and a-15:0 acids in L. pneumophila, even though these two acids are completely resolved and separated by $5.6 \mathrm{~s}$ on the capillary column used in our study. Whatever the reason for the discrepancy, it is important that these differences be noted and corrected as we have found that the uniqueness of the cellular fatty acid composition of Legionella provides a valuable chemical marker for rapid differentiation of this genus from other gram-negative bacteria $(3,4,6,7)$.

We thank Dannie Hollis for providing the Moraxella cultures.

\section{LITERATURE CITED}

1. Feeley, J. C., R. J. Gibson, G. W. Gorman, N. C. Langford, J. K. Rasheed, D. C. Mackel, and W. B. Baine. 1979. Charcoal-yeast extract agar: primary isolation medium for Legionella pneumophila. J. Clin. Microbiol. 10:437-441.

2. Moss, C. W. 1981 . Gas-liquid chromatography as an analytical tool in microbiology. J. Chromatogr. 203:337-347.

3. Moss, C. W., W. F. Bibb, D. E. Karr, and G. O. Guerrant. 1983. Chemical analysis of the genus Legionella: fatty acids and isoprenoid quinones, p. 375-381. In H. LeClerc (ed.), Gramnegative bacteria of medical and public health importance: taxonomy-identification-applications. Institut National de la Santé et de la Recherche Médicale, Paris, France.

4. Moss, C. W., and S. B. Dees. 1979. Further studies of the cellular fatty acid composition of Legionnaires disease bacteria. J. Clin. Microbiol. 9:648-649.

5. Moss, C. W., A. Kai, M. A. Lambert, and C. Patton. 1984. Isoprenoid quinone content and cellular fatty acid composition of Campylobacter species. J. Clin. Microbiol. 19:772-776.

6. Moss, C. W., R. E. Weaver, S. B. Dees, and W. B. Cherry. 1977. Cellular fatty acid composition of isolates from Legionnaires disease. J. Clin. Microbiol. 6:140-143.

7. Orrison, L. H., W. B. Cherry, R. L. Tyndall, C. B. Fliermans, S. B. Gough, M. A. Lambert, L. K. McDougal, W. F. Bibb, and D. J. Brenner. 1983. Legionella oakridgensis: unusual new species isolated from cooling tower water. Appl. Environ. Microbiol. 45:536-545.

8. Pasculle, A. W., J. C. Feeley, R. J. Gibson, L. G. Cordes, R. L. Myerowitz, C. M. Patton, G. W. Gorman, C. L. Carmack, J. W. Ezzell, and J. N. Dowling. 1980. Pittsburgh pneumonia agent: direct isolation from human lung tissue. J. Infect. Dis. 141:727732 .

9. Sugimoto, C., E. Miyagawa, M. Nakazawa, K. Mitani, and Y. Isayama. 1983. Cellular fatty acid composition of Haemophilus equigenitalis and Moraxella species. Int. J. Syst. Bacteriol. 33:181-187. 